\title{
LA TEORÍA PEDAGÓGICA DE JOSÉ VASCONCELOS
}

Ma. del Carmen Bernal González México., Trillas., 2005., 93 págs.

\section{LA PREGUNTA POR LO MEXICANO}

¿Cómo es el mexicano?, ¿Cómo se comprende a sí mismo?, ¿cuál es su forma de interpretar la realidad y de relacionarse con ella?, ¿cuál es la educación que mejor responde a su forma de ser?, ¿qué actitudes y aptitudes le permitirán enfrentarse exitosamente a las oportunidades y retos que le ofrece el mundo actual?, ¿cómo ha de lucrar lo global sin sacrificar lo específico? Éstas serían sólo algunas preguntas que pueden avizorarse detrás del título de la obra de María del Carmen Bernal, La teoría pedagógica de José Vasconcelos.

Son, sin duda, cuestiones interesantes, complejas que flotan en el ambiente y que, según Bernal, vale la pena reexaminar a la luz que nos ofrecen las respuestas que contemplan la situación mexicana desde dentro. Con esa intención, la autora se da a la tarea de explorar histórica, crítica y pedagógicamente la teoría de un mexicano que habla a los mexicanos, a fin de rescatar, de la fecundidad de su propuesta educativa, los ideales que la sustentan, los valores que la dirigen y las fuerzas que la dinamizan. Dirige su indagatoria hacia el discurso vasconceliano que, por su probada profundidad teórica y fecundidad práctica, constituye todo un acontecimiento de la historia de la educación en América. 


\section{UN PROFETA INCOMPRENDIDO}

Con su publicación, la doctora Bernal ofrece un panorama sintético inteligente y actualizado de la labor pedagógica de un filósofo, político, educador y literato que ha sido considerado, por algunos, un profeta incomprendido y, por otros muchos, el maestro de América. Imaginativo, visionario y enérgico, José Vasconcelos (1882-1959) parte del convencimiento de que la educación, deber y derecho al que todo mexicano debe tener acceso, es la solución a los problemas sociales que vive México. A partir de esa convicción, el autor del Ulises criollo emprende un acucioso estudio antropológico, psicológico, político y pedagógico de la estirpe mexicana, con el fin de diseñar una filosofía de la educación que responda fielmente a la vocación de México en el mundo y en la historia; filosofía capaz de dar sentido al desarrollo de metodologías acordes al estilo y modo de ser mexicanos. Por eso, la teoría pedagógica de José Vasconcelos —señala Bernal-atiende al ser del hombre en toda su integralidad: dando a la educación intelectual su radical importancia, se extiende a las dimensiones física, ética y estética que conforman la personalidad humana.

\section{REVOLUCIÓN POLÍTICA Y REVOLUCIÓN EDUCATIVA}

Del ambicioso proyecto vasconceliano, Bernal enfatiza dos aspectos particularmente rescatables para la educación del siglo XXI: su teoría pedagógica y su propuesta de educación estética. Con estas herramientas, integradas en un discurso original, fundado sobre una filosofía abierta, Vasconcelos encabezó, en su momento, la campaña más importante que haya tenido la cultura mexicana. Con él, la revolución socio-política vino a fecundar los terrenos de la 
educación; o mejor dicho, con Vasconcelos - y el Ateneo de la Juventud-, la revolución cultural se anticipó, con fertilidad manifiesta, a la revolución armada.

Inteligente, culto y trabajador incansable, el autor de $L a$ raza cósmica, se propuso despertar la conciencia de una cultura nacional asentada sobre la raza, el idioma y la tradición. La norma de esa cultura debía ser la realización de los más altos y universales valores del espíritu: Por mi raza hablará el espíritu, según postula el lema que acuñó para el escudo de la Universidad de México.

\section{Una Teoría Fecunda}

Especialista en el tema, la doctora Bernal condesa en esta edición parte de una investigación más amplia. Quiere mostrar que José Vasconcelos (epónimo de la magna biblioteca recientemente inaugurada) no es un personaje congelado en la historia de las utopías pedagógicas.

En efecto: la teoría vasconceliana fue, en su momento -y en más de un sentido, sigue siendo_- una palmaria constatación de que no bay nada más práctico que una buena teoría. De hecho, un parecer muy generalizado sostiene que el aspecto constructivo más importante de la administración obregonista fue el educativo y cultural que dirigió, con genio, certeza y eficacia, José Vasconcelos. Siendo rector de la Universidad Nacional, delimitó las responsabilidades y derechos de esta máxima Casa de Estudios; y siendo Ministro de Educación, rediseñó las funciones de una renovada Secretaría de Educación Pública. 
A partir de ahí, los resultados prácticos, concretos de su teoría fueron múltiples y de probada trascendencia. A modo de ejemplo, basta recordar que bajo su dirección se reorganizó la enseñanza y se renovaron los planes de estudio de todos los niveles. Se intentó - y se logró en gran medida- llevar la alfabetización y la educación fundamental por todos los ámbitos del país mediante las misiones culturales. Se multiplicaron las escuelas rurales encargadas de custodiar y difundir los valores de las culturas indígenas: lenguas, artes populares, música y danzas de cada región. De las comunidades indígenas partieron los alumnos más distinguidos a continuar sus estudios en la Ciudad de México.

Se trató de identificar a todos los mexicanos bajo la bandera de la cultura y de una axiología plural, abierta y ambiciosa. Mediante una original y amplia red de bibliotecas, puso al alcance de todos no sólo una gran cantidad de libros de texto, sino también valiosas colecciones de las más importantes obras de la literatura universal: Platón, Plotino, San Agustín, Göethe, Dante, Rolland, Tagore...

\section{Calidad Educativa y Profesionalidad Docente}

Convencido de que todo intento de mejorar la calidad educativa de México debe comenzar por perfeccionar la calidad personal y profesional de sus educadores, Vasconcelos abordó con energía la imprescindible reforma de la profesión docente. Entrevió la importancia de la educación para el trabajo, y propuso su inclusión en el sistema educativo mexicano. Invitó a colaborar en esta ingente revolución pedagógica, a la maestra y poeta chilena Gabriela Mistral, así como a un grupo selecto de educadores. 
Se impulsó, con tal propósito, la construcción de un moderno edificio para la Escuela Normal en la capital. Se favoreció la creación de escuelas normales en otras ciudades y en el campo. Se construyó el Estadio Nacional; se rehizo el edificio del antiguo convento de la Encarnación, en el que se instaló la Secretaría de Educación, creada el 28 de septiembre de 1921 por su iniciativa. Se dio fuerte impulso a la enseñanza técnica, industrial y comercial; propició el desarrollo de las artes populares.

En fin: no hace falta prolongar innecesariamente esta enumeración de logros, baste señalar que no es posible entender el impacto artístico y social del muralismo mexicano (Roberto Montenegro, Diego Rivera, José Clemente Orozco, David Alfaro Siqueiros y muchos más), sin el patrocinio directo y entusiasta de Vasconcelos.

\section{Educación e Identidad Nacional}

Al reexaminar la teoría pedagógica de José Vasconcelos, Carmen Bernal no pretende, a mi modo de ver, curiosear eruditamente en el pasado. Pretende, más bien, rescatar sus aspectos cardinales y aprovechar su utilidad práctica. Somete a revisión el discurso vasconceliano a la luz de la problemática actual de México. Con visión integral y decantada, entresaca aquellos elementos útiles para la comprensión de la autoformación progresiva de la identidad nacional. Logra, así, una obra que se convierte en amable invitación a adentrarse en el pensamiento de un autor que se pronuncia por una educación que sea: la puerta de entrada a la civilización y principalmente la forma de inmortalizar la propia estirpe a través de la cultura. 
Es verdad que, a pesar de la ingente actividad teórica y práctica de Vasconcelos, se dieron circunstancias ideológicopolíticas que, en más de un sentido, hicieron abortar su ambicioso proyecto. Aun así, Bernal subraya aquellos aspectos nucleares que, por encima de los vaivenes ideológicos y coyunturales, mantienen el carácter radical y permanente de todo principio pedagógico. De este modo logra mostrar, una vez más, el porqué la historia se ha encargado de añadir el nombre de José Vasconcelos a la larga nómina de los grandes constructores de una ciencia pedagógica original, de perfiles específicos y valores universales: Quiroga, Sarmiento, Bello, Martí, Mistral, Dewey, etcétera. Ciencia pedagógica, a veces controvertida, pero siempre fecunda, ajustada a la idiosincrasia de los pueblos de la América y, al mismo tiempo, abierta y solidaria con los grandes ideales, aportaciones y problemas del mundo.

\section{RIQUEZA PERSONAL Y BAGAJE CULTURAL}

Por fortuna, la investigación de Bernal no se empantana en las complejidades socio-políticas, siempre discutibles, que enmarcan la vida y la obra de Vasconcelos.

Tampoco se limita a hurgar nostálgicamente en el pasado, ni pretende una regresión histórica. Trata, más bien, de descifrar lo que constituye el núcleo axiológico fundamental de un sistema educativo del que, directa o indirectamente, se han beneficiado muchas generaciones de mexicanos. Teoría que apunta — concluye la autora- a descubrir y desarrollar la riqueza personal y resaltar el propio bagaje cultural del mexicano.

Se trata, en efecto, de una teoría de gran originalidad que parte del hecho innegable de que la educación, además de 
ser una labor radicalmente personal, es, al mismo tiempo, un problema de interés nacional. La problemática educativa no debe, por tanto, subordinarse a las pasiones políticas de partido; involucra la educación, el destino de millones de seres humanos que, en su existencia y en su coexistencia, reclaman una formación integral adecuada y eficaz para afrontar la vida y proyectarla hacia un futuro más libre y justo, tanto en lo personal, lo familiar y lo social.

De ahí que la obra de Bernal destaque, de la propuesta vasconceliana, un hecho muy sencillo que, por elemental, suele pasar inadvertido pero que la fundamenta, firme y solidamente: él conoció con profundidad, entendió con lucidez y atendió con fervor todo lo mexicano. Comprendió que un pueblo como el nuestro, que por circunstancias únicas ha logrado definir una fisonomía también única, no puede ser receptivo sino de una cultura propia, legítima, que responda a las necesidades, exigencias y expectativas de su peculiar carácter y del ambiente singular en que discurre su existencia. Trata — afirma la autora- de rescatar la estirpe mexicana; el modo propio y específico del ser y hacer mexicanos, para consolidar la propia unidad e identidad nacionales. Busca develar, desenvolvery desarrollar todas las capacidades de los mexicanos, devolviéndoles la confianza en sí mismos y el amor por lo suyo.

\section{HACIA UN PATRIOTISMO MAYOR}

Paralelamente se subraya que la obra de Vasconcelos, con ser genuinamente mexicana, nacional, no se encapsula en los estrechos límites de un nacionalismo miope. 
El de Vasconcelos es un proyecto abierto, cósmico, en el que los elementos exógenos se incorporan de manera natural al modo de ser vernáculo. No hay entonces paradoja, al decir que Vasconcelos buscaba, como resultado de su propuesta formativa, un espíritu amplio, universal, magnánimo, a través de las formas nacionales.

Él mismo lo explica así: "Movido por el afán de dotar a la educación nacional del ideal que le falta, hice otro esfuerzo desesperado. Consistió en ampliar el plan patriótico, asentándole en la lengua y en la sangre. Pretendía revivir un parentesco amplio con los demás países de habla hispana y hacer del hispanoamericanismo una especie de patriotismo mayor.

Gracias a esta apertura, el discurso vasconceliano no se congeló en la historia, ni se paralizó en la geografía. Trascendió y ostenta, aun en nuestros días, rasgos verdaderamente universales de innegable aplicabilidad y vigencia, a tal punto que, para Samuel Ramos: Casi toda la pedagogía autóctona posterior a Vasconcelos, no ha hecho sino resaltar más sus méritos y casi (y subrayo casi) todas las novedades que se han intentado, no han pasado de ser una imitación torpe de lo extranjero.

\section{EL HOMBRE Y SU OBRA}

Como se ve, la empresa vasconceliana representó, en su momento, una verdadera revolución educativa y cultural. Revolución orientada — señala la autora- a la regeneración del espíritu a través del impulso a la cultura y a la educación.

Sabemos bien que tal revolución surge y se desarrolla precisamente en un delicado giro de nuestra historia, en el que 
México pasa de una situación socio-política y cultural, a otra muy diversa. Gracias a la obra de Bernal tenemos una comprensión más nítida, más próxima, de ese apasionante giro histórico del que es posible rescatar lo más esencialmente valioso del trabajo de Vasconcelos, a cuya labor se oponían ácidos prejuicios y sistemas envejecidos que había que remover o renovar por completo. Una tarea de tal magnitud, que venía a imponer nuevas normas y a señalar nuevos caminos requería, para su maduración, un lapso mayor que el que tarda una generación en educarse para colmar sus frutos.

Atinadamente, Carmen Bernal deja hablar a Vasconcelos mediante citas oportunas, para que sea él mismo quien nos muestre su asombrosa actualidad como precursor de la educación posmoderna. En este diálogo, logramos intuir una plena identificación del hombre con su obra. Identificación que explica la pasión, la fuerza, el entusiasmo con que Vasconcelos trabajó y hacía trabajar a sus colaboradores en la empresa pedagógica que él dirigía en la Universidad, el Ateneo o el Ministerio.

Para comprender mejor su teoría, Bernal nos ofrece un retrato de la ínclita personalidad del autor de Robinson a Odisea: pedagogía estructurativa. Más filósofo, educador y escritor que político ${ }^{1}$, de carácter apasionado y firme, optimista

Político en el buen sentido del término (no lo que los antiguos griegos llamaban hosteoteeteta (buscador de hueso, perro que medra con la necesidad pública). Esto — que conste- no lo dice Marycarmen, ni lo digo yo: lo dice don José Ángel Cevallos en su obra Examen de sujetos, en donde estudia la personalidad de Vasconcelos y otros coetáneos. Se sabe que, a propósito del incidente de las elecciones (¿fraudulentas?) en las que Vasconcelos fue uno de los candidatos a la presidencia, sus alumnos le insistían: "Maestro, cuando usted muera deberá ser sepultado, por elemental justicia, en la rotonda de los hombres ilustres". A lo que él replicaba enfáticamente: "iSí, pero como presidente de México, no como filósofo!”". (¿Ya desde entonces "se caía el sisteman?). 
y magnánimo, mientras estuvo al frente de la educación nacional, ésta recibió un fuerte impulso espiritual y operativo que contagiaba energía. Se palpaba una inteligencia y un pensamiento director; se le reconocía bonhomía, talento y trabajo. Reunía el sentido de la realidad con un idealismo que se remontaba, a veces, hasta altitudes místicas. Pero su misticismo no era puramente especulativo, sino dinámico y propulsor de una voluntad potente, arrolladora, como una fuerza de la naturaleza.

Pero en México — señala Samuel Ramos- nadie puede contar con tanto tiempo para realizar, dentro del gobierno, una obra continuada; además, cada funcionario que llega se siente con la obligación de acabar con la obra de su antecesor. Cuando Vasconcelos apenas tenía cuatro años como jefe de la educación nacional, interrumpió bruscamente su obra, a causa de incidentes politicos que lo obligaron a salir del Ministerio. Su obra, no obstante su innegable fecundidad práctica, quedó a medio empezar, como un gran boceto genial en el que se trazaban los lineamientos esenciales, pero aún impreciso en los detalles.

\section{EDUCACIÓN ESTÉTICA: LA ETERNA ESTÉTICA}

La publicación que nos ocupa presta especial atención al empeño vasconceliano de coronar los planes de estudio con la educación estética: el rostro más incierto de la cultura nacional. Demuestra que la vocación del mexicano, comprende mucho más que una simple sensibilidad para apreciar lo bello. Cada mexicano nuevo — considera él_puede y debe ser un hombre completo, lo que es obligación de todos hacer factible... 
México — sigue afirmando- es una fuerza natural bumana; [...] una gran cosa que muchas veces estamos en la imposibilidad de definir. México debe ser bueno para todos y hacer por tanto, buenos a todos; México por consiguiente es la obra de los grandes ciudadanos. Ve, en la estirpe mexicana, el mayor tesoro que hará de México una nación culta y civilizada, siempre y cuando se le ayude a ser mejor y a desarrollar todas sus capacidades y posibilidades.

Por eso, la esencia de su proyecto pedagógico consiste en desarrollar y promover, mediante la educación, un concepto de identidad cultural mexicana que se funde en el reconocimiento de nosotros mismos mediante la identificación de la propia cultura y de los símbolos y signos que guardan nuestra historia (por ejemplo, las tradiciones y los monumentos nacionales); educación cuya expresión deba darse a través del desarrollo de la sensibilidad estética y el cultivo de las manifestaciones artísticas.

\section{México: un Pueblo Estético}

Vasconcelos — señala Bernal- desarrolla la capacidad de expresión artística y fomenta la unidad con la propia estirpe mediante el lenguaje, la tradición, el sentimiento y el gusto; de abi el fomento de las artes y lo cotidiano. En definitiva, pretende que los mexicanos aprendan a vivir con más creatividad, fascinación, unión y alegría.

A esto apunta su propuesta acerca de la educación estética, no como simple desarrollo de la sensibilidad — que, dicho sea de paso, es lo más individualista y manipulable del ser humano, y que muchas veces se ha querido educar así a los 
pueblos para mantenerlos y tratarlos en ese nivel- No, para Vasconcelos, la educación estética apunta a lograr el ideal educativo de una formación integral de la personalidad: Siendo México un pueblo eminentemente estético — considera Bernal_, resulta paradójico que las artes no hayan sido prioridad en la educación mexicana.

Porque la educación integral, para la ciencia pedagógica, sólo puede entenderse en su sentido más radical y auténtico: como aspiración al UNUM trascendental del ser.

Porque Vasconcelos, hombre moderno de profunda formación clásica, comprendió muy bien que toda auténtica educación ha de tender a la unidad; a la armonía en la unidad, que es lo que entendemos como PULCHRUM, como estética, armonía o belleza. No como mero revestimiento postizo, apariencia exterior o artificios de estilo, sino como splendor veri (como el esplendor de la verdad), splendor boni (como el esplendor del bien), splendor unitatis (como el esplendor de la unidad). Es la integralidad como el esplendor de la dignidad humana; dignidad que es, a la vez, plenitud y proyecto vital. Integralidad en la que la dimensión ética que caracteriza todos los actos del ser humano, muestra que su vida es camino hacia su propia realización como persona.

Vista así, la formación estética viene a coincidir con la excelencia de la existencia humana; excelencia que es como cierta bondad de fondo que surge, que se manifiesta - exducere - como una especie de epifanía del brillo propio de la personalidad. 


\section{PRECURSOR DE LA INTELIGENCIA EMOCIONAL}

Es natural, pues, que la autora no considere exagerado señalar al autor de obras como Estética; Filosofía estética y Ensayos sobre el monismo estético, como un verdadero precursor de la ahora llamada inteligencia emocional.

Con su teoría del conocimiento emocional, Vasconcelos atribuye a la emoción una serie de cualidades que, desde el punto de vista educativo, es preciso tener en cuenta: la fuerza de la expresión creativa, la inspiración como resultante de las emociones y el conocimiento distinto que aportan de la realidad. Para él, la emotividad del mexicano posee una fuerza y energía peculiares, que explican el auténtico aprecio que los mexicanos poseen por los valores de la propia cultura. Fuerza, energía y valores que deben ser atendidos y desarrollados en todo proyecto educativo nacional. De ahí la importancia que este modelo pedagógico concede a las emociones y la estética en la existencia humana, y especialmente en el modelo educativo mexicano.

En este discurso, la Historia Patria contiene elevadas e indelebles lecciones. De ahí que Bernal subraye la gran importancia que se concede a la conciencia del pasado, sobre todo cuando Vasconcelos enfatiza que: "Los verdaderos mexicanos tiemblan ante la bistoria. Sienten ya en sus carnes los dolores que quisieran evitar a sus bijos y a los bijos de sus bijos".

En esta labor de alerta, desea participar la obra de la doctora Bernal, encaminada a resaltar los conceptos, principios $y$ directrices que sustentan el pensamiento del precursor de la educación posmoderna, con el propósito de ayudar a los 
educadores mexicanos en el rescate de la herencia educativa del caudillo cultural de México.

La autora concluye que los valores educativos propuestos por el autor siguen con vida, la perspectiva del tiempo, la memoria bistórica y la audacia de los profesionales de la educación seguirán ayudando a descubrir la grandeza de este personaje que tanto ha becho por la educación mexicana. Vasconcelos es un pedagogo mexicano para los mexicanos, abi radica su singularidad y creatividad. Su mejor legado fue dejar por escrito y en obras tangibles que la educación es el mejor patrimonio de la civilización.

Héctor Lerma Jasso 


\section{REFERENCIAS BIBLIOGRÁFICAS}

ABBAGnANO, N. y VISALBERGHI, A., Historia de la Pedagogía., FCE., México., 1990.

CHRISTLIEB, A., Monopolio educativo o unidad nacional.

Un problema de México., Ed. Jus., México., 1962.

BERNAL GONZÁlEZ, Ma. del Carmen., La teoría pedagógica de José Vasconcelos., Trillas., México., 2005.

FELL, C., José Vasconcelos: los años del águila., Instituto de Investigaciones Históricas., UNAM., México., 1989.

HERnÁnDEZ, J., et al., Conferencias del Ateneo de la Juventud., UNAM., México., 1984.

LATAPI, P., Un siglo de educación en México., t. II., Biblioteca Mexicana., FCE., México., 1998.

LARROYO, F., Historia de la Educación en México., Porrúa., 1852.

RAMOS, Samuel., "Historia de la Filosofía en México"., Obras completas., t. II., UNAM., México., 1998.

SANTIAGO, A., Las misiones culturales., SEP-Setentas., No. 113., SEP., 1972. 

rpp 09 5/11/07 12:00 PM Page 176 